В.М. Розин

\title{
ОСОБЕННОСТИ СОВРЕМЕННОЙ РОБОТОТЕХНИКИ
}

\begin{abstract}
Аннотация. В статье рассматриваются особенности современной робототехники, а также ситуация, породившая настоящий бум в этой области. Разводятся и характеризуются два направления развития робототехники: в одном, опирающемся на старую концепцию робототехники, разработчики, создавая свои изделия, стремятся имитировать вид животных или людей, в другом - концепция робототехники опирается на программирование, средовые представления, понятие современной технологии. Обсуждается, почему робототехника была осознана достаточно поздно, а также, ситуация (зона ближайшего технологического развития), в которой сложилась робототехника. Анализируются возможности современной робототехники, а также некоторые проблемы, связанные с ее развитием. При рассмотрении этих вопросов применялись методы сравнительного анализа, постановки проблем, построения новых понятий, построения кейсов, генетической реконструкции, ситуационный анализ. В результате удалось охарактеризовать особенности современной робототехники и ситуацию, в которой она сложилась. Были разведены и описаны два направления развития робототехники: один ориентированный на антропологический идеал, другой - на идеи программирования, современной технологии, организацию особой среды, представляющую собой естественные образования, жизнь и особенности которых мы пока плохо понимаем.
\end{abstract}

ключевые слова: робот, Робототехника, технология, изделие, развитие, программирование, среда, сети, системы, автономия.

Abstract. This article explores the nuances of the modern robotics, as well as the cause for the current boom in this area. The author determines and characterizes two directions in development of robotics: in one, which leans on the old concept of robotics, the developers attempt to imitate animals or people; in the other - the concept of robotics leans on the programming, environment perceptions, and understanding of modern technology. A discussion is held on why the robotics was created fairly late, as well as the situation (the zone of nearest technological development), in which robotics has been established. The article analyzes the capabilities of modern robotics as well as some issues related to its development. As a result, the author was able to characterize peculiarities of modern robotics and the situation in which it emerged. The author defines and describes two directions of development of robotics: one is oriented towards the anthropological ideals; the other - towards the ideas of programming, modern technology, organization of special environment representing natural formations, life and nuances of which we have yet to fully understand.

Keywords: Robot, Robotics, Technology, Product, Development, Programming, Environment, Network, System, Autonomy.

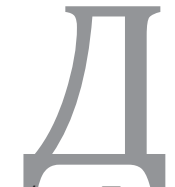

аже неспециалист, видя периодически на экранах телевидения роботов и слыша разговоры о них, догадывается, что в этой области происходит настоящий бум. Те же, кто следят за новостями в технике и знает, хотя бы понаслышке, об интересе к роботам в прошлом веке, кто, может быть, читал К.Чапека и А.Азимова и даже слышал о законах робототехники, такой читатель может задуматься и задаться вопросом, а почему сегодня снова заинтересовались роботами, вкладываются немалые средства в их изобретение и разработку? Я отношу себя как раз к этой второй категории интересантов и помню, давно удивлялся тому, что писатели были первыми, как бы мы сегодня сказали, «роботоманами», в эпоху, когда робототехника делала только первые робкие шаги.

Конечно, что понимать под робототехникой. Недавно мне в руки попалась работа «Рождение и основные этапы развития робототехники», где описывались технические изобретения, начиная с античности до наших дней: механические голуби, утки и собаки, куклы в человеческий рост, которые кланялись, говорили и писали, первый автоматический ткацкий станок Жозефа Мари Жаккарда, управляемый с помощью перфокарт, 


\section{Теория и методология управления}

испытания первых роботов-солдат - «электрического человека» Фрэнка Рида, стрелявшего электрическими разрядами, и механического солдата Арчи Кемпиона, который, как утверждают, даже участвовал в боевых действиях [1] Bсе эти и многие другие похожие изобретения авторы относили к истории робототехники. С другой стороны, известно, что термин робототехника впервые вводит в рассказе «Runaroud» Айзек Азимов (1942), и там же появляются «Три Закона Робототехники»: 1. Робот не может причинить вред человеку или своим бездействием допустить, чтобы человеку был причинен вред. 2. Робот должен подчинятся командам человека, если эти команды не противоречат первому закону. 3. Робот должен заботиться о своей безопасности, пока это не противоречит первому и второму закону.
Возникает вопрос: может быть, о робототехнике стало возможным говорить только после Айзека Азимова, ведь как может существовать нечто, для чего еще нет слов? К тому же ведь в современной науке о технике исходят из того, что техника - это массовый индустриальный феномен, а в начале 40-х годов прошлого века о промышленном производстве роботов приходилось только мечтать, чем Азимов успешно и занимался в своих рассказах. Такое производство состоялось только в наше время; нельзя ли тогда предположить, что робототехника сложилась только в конце прошлого, начале нашего века? А кого же тогда, если не роботов создавали изобретатели прошлых веков? Подвесим пока этот вопрос и пойдем дальше.

Прочитав в газете ЕС статью «"Шершеньубийца"» на страже Израиля» [2], я понял, что

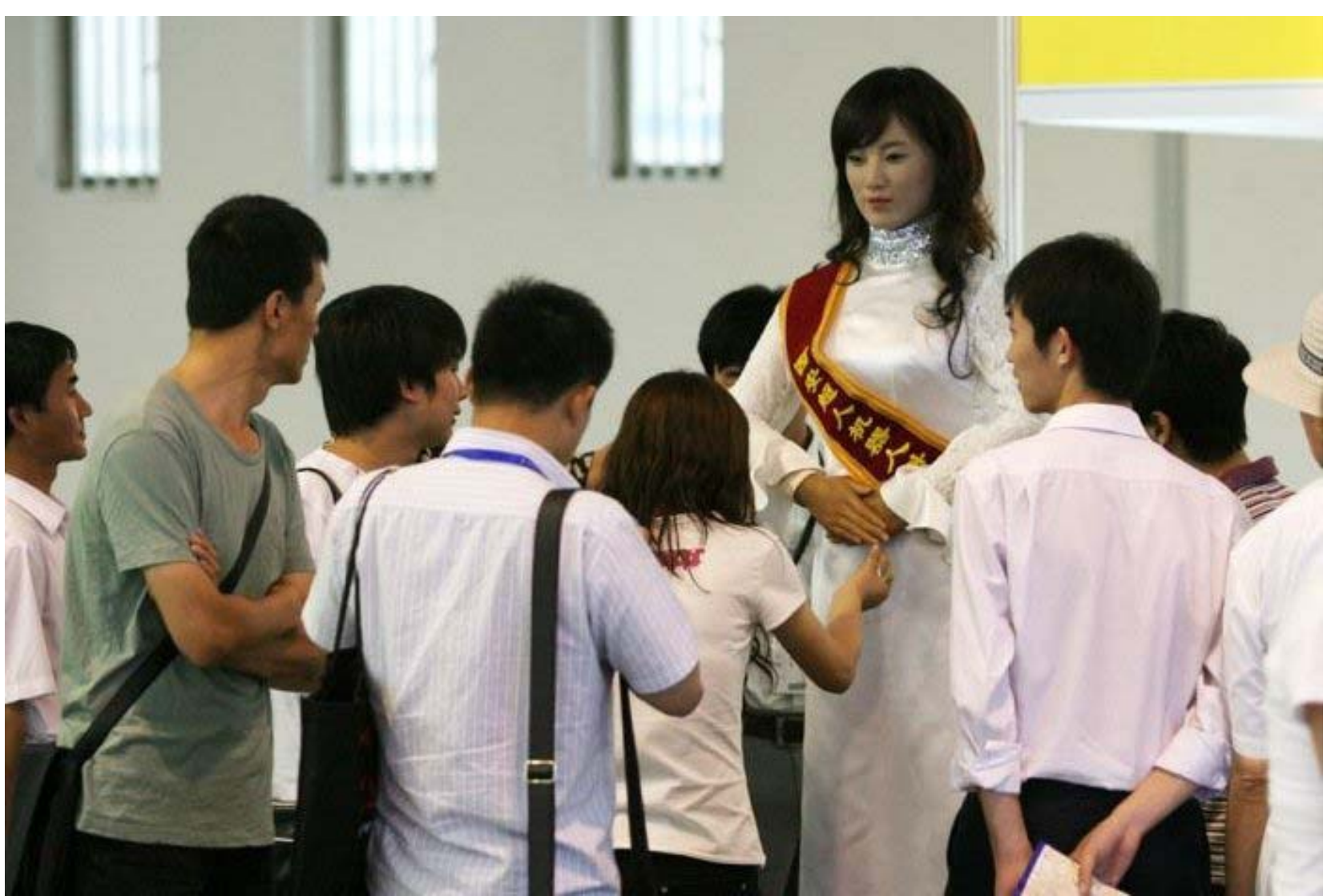

Рисунок 1 


\section{Тренды и управление 1(13) • 2016}

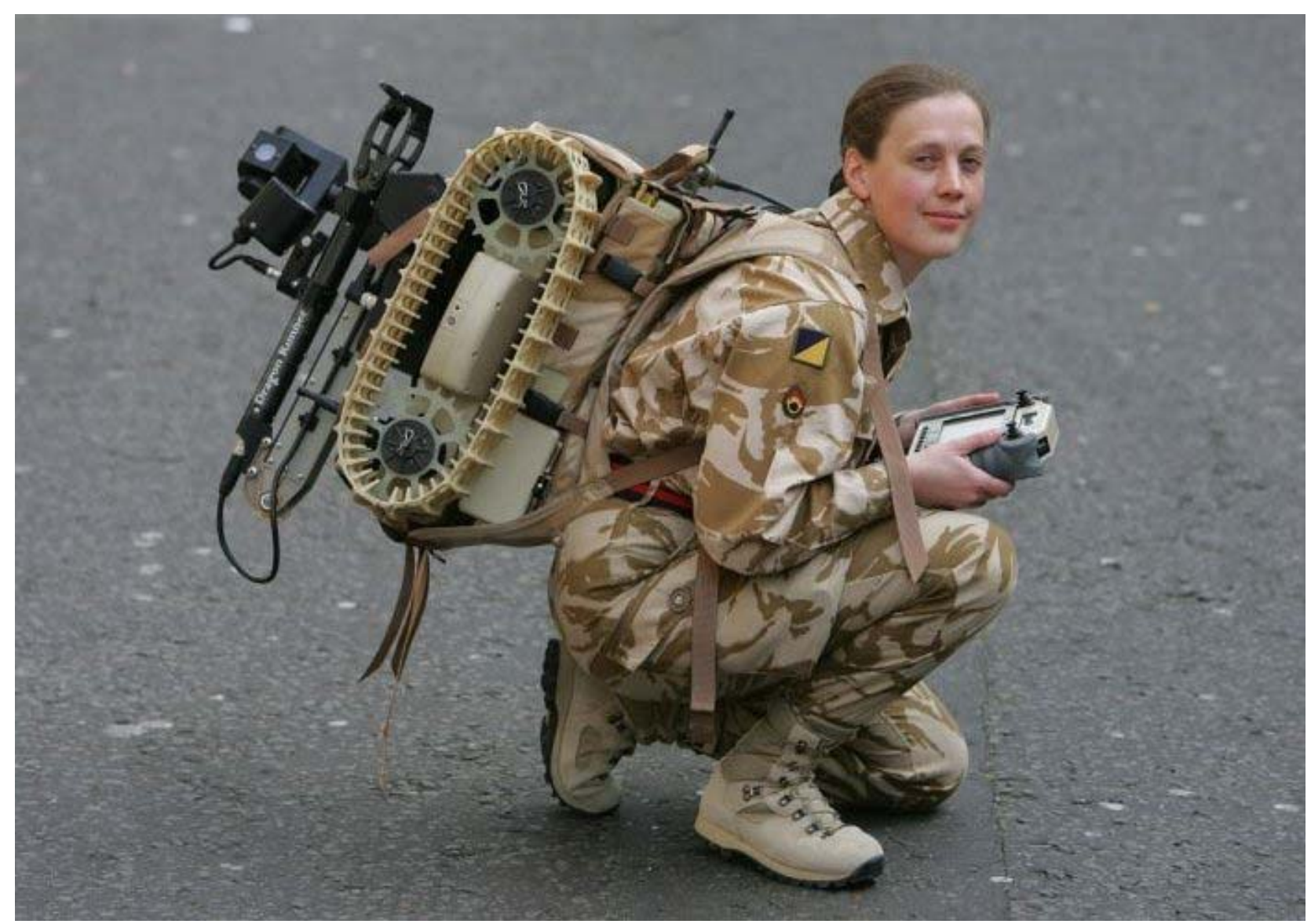

Рисунок 2

в развитии современной робототехники можно выделить два подхода (направления). В первом изобретаются, так сказать, «антропоморфные роботы», имитирующие своим внешним видом людей или животных (человека, собак, змей, пчел, мух и пр.).

Во втором направлении изобретатель не связывает себя требованием подобного сходства; таковы например, беспилотники, реактивные самолеты, в которых ряд операций может контролировать автопилот, роботы-разведчики - дистанционно управляемый малогабаритный вездеход или резиновый шар размером с теннисный мяч, оборудованный камерами и другими разведывательными средствами.

Если подумать, первый поход формировался, опираясь на старую концепцию робототехники. А именно на концепцию искусственного интеллекта и предположение, что роботы будут развиваться, реализуя антропоморфный идеал (не просто помогать человеку, но и мыслить, понимать и вести себя, как он, - отсюда законы робототехники). С этим же связаны споры, может ли машина быть умнее человека и, например, обыграть его в шахматы. При этом, что кажется вполне естественным, отождествляют работу суперкомпьютера с мышлением человека, в частности, апеллируя к тому, что в мае 1997 года компьютер Deep Blue в матче из 6 партий обыграл чемпиона мира по шахматам Гарри Каспарова. Но такое отождествление, на мой взгляд, не совсем законно. Во-первых, потому, что мышление человека - феномен психологический, семиотический и социальный (мозг только субстрат мышления), а не машинный. Во-вторых, сторонники компьютерного мышления не понимают, что программы Deep Blue включали в себя не только переборы и сравнения ходов и их следствий, но также 


\section{Теория и методология управления}

обобщение лучших шахматных партий и даже практику подготовки к шахматным чемпионатам, которую разработал и успешно использовал наш чемпион мира М. Ботвинник. В этом смысле Каспаров сражался не с машиной, а с воплощенной в машинной среде шахматной культурой; культура же на порядок мощнее индивида [3].

В настоящее время концепция робототехники, распространяемая и на первое направление производства роботов, совершенно иная. Робот и бот - это сложные программы (в материальных инженерных устройствах или в электронном виде), позволяющие автоматизировать рабочие процессы, заменить в ряде случаев действия человека (но не его самого), выполнить опасные или силовые операции, или процессы, протекающие на больших скоростях. Неудивительно, что многие разработчики считают, что основа робототехника - это программирование, создание компьютерных языков, плат, систем. А чем если не электронными роботами (ботами) являются сложные компьютерные вирусы? Без так понимаемой роботизации в настоящее время невозможно решать многие современные задачи, например, такие. «Международный институт передовых телекоммуникационных исследований (2006) совместно с компанией Honda разработал новый тип связи между человеком и машиной. Робот-манипулятор подчинялся мыслям испытуемого без всякой видимой связи с ним. Новый интерфейс мозг-машина (Brain Machine Interface) основан на ежесекундном анализе картины активности участков мозга<... Миниатюрные роботы-коллективисты способны взаимодействовать друг с другом и обмениваться информацией. У каждого бота имеется произвольный набор параметров - “генов”, определяющих поведение. В процессе исследований отбирали ботов, наиболее эффективно отыскивающих пищу. Их “геномы” затем смешивались, что приводило к постепенной эволюции» [1].

Тем не менее, стоит отметить, что в рамках этого нового понимания робототехники мечта сделать робота умнее человека до конца не умирает. Вот, что можно в связи с этим прочесть в Интернете. «Виртуальный игрок в Unreal Tournament 2004 по имени $\mathrm{UT}^{\wedge} 2$, созданный учеными Техасского университета в Остине, завоевал приз на чемпионате BotPrize, как бот, которому удалось обмануть большинство судей, выдав себя за человека. Боты в состязании играли против других ботов и такого же количества людей. У людей кроме обычного набора оружия было «судейское ружье», чтобы помечать оппонента как бота или человека. Победивший бот набрал рейтинг «человечности» $52 \%$, а средний рейтинг у людей составил лишь 40\%. Таким образом, UT^2 прошел «тест Тьюринга», согласно которому, если машина может убедить человека в том, что она человек, значит, она способна мыслить. Сам Тьюринг предсказывал, что компьютеры пройдут тест к 2000 году. Как объясняют разработчики, чтобы выдать бота за человека, его поведению пришлось придать элементы иррациональности, свойственные людям. Но основной механизм поведения в игре, объясняют ученые, создан путем нейроэволюции - процесса, когда нейросеть, реализующая искусственный интеллект, проходит через серию испытаний на выживание в условиях игры. Выживающие нейросети сохраняются, остальные отбрасываются. Из выживших путем случайной мутации создаются наследники. «Эволюция» продолжается до тех пор, пока не появляются сети с желаемым поведением» [4].

Наконец, во втором направлении робот или бот не связаны законами робототехники (например, уже на выходе американские роботы «совершенные солдаты») и развиваются роботы не для того, чтобы на каких-то правах войти в сообщество людей, а просто как сложная техника на службе человека.

Второе принципиальное отличие нового понимания робототехники можно сформулировать примерно так. Роботы - не отдельные изобретения гениальных инженеров, а часть проектируемой технической среды. Эту среду характеризует одна важная особенность. Известно, что роботы обладают определенной автономией. Но в отличие от традиционной техники (орудий, механизмов, машин), где в управлении всегда принимает участие человек, современные роботы управляются компьютерными программами, а эти программы, в свою очередь, могут управлять другими программами (которые, например, меняют режимы работ автоматов) Принципиально, что автономия современных роботов, так сказать, опосредованная и средовая (в 


\section{Тренды и управление 1(13) • 2016}

отличие от старых роботов, где автономия обеспечивалась техническим устройством, например, часовым механизмом, входившим в состав самого робота). Скажем, могут ли современные роботы работать без электричества, могут ли их проектировать и создавать без компьютеров и Интернета, без исследовательских и инженерных лабораторий и фирм, без капиталовложений, даже без капиталистической конкуренции? А ведь все перечисленные системы и институции представляют собой сети и особую социальнотехническую среду.

Третье отличие такое. Робототехника - это не инженерная деятельность (хотя инженерия одна из составляющих робототехнических разработок), а современная технология. Не «технология в узком понимании», характерная для индустриального машинного производства, ориентированная на качество, экономию, операциональное представление производственной деятельности [5]. Робототехника - это технология, включающая в себя самые разные виды деятельности - исследование, проектирование, инженерные разработки, планирование и разворачивание процедур внедрения, анализ предполагаемого рынка и потребителя и др. Все эти виды деятельности требуется соорганизовать, нацелить на создание единого технического изделия, в данном случае роботов, и необходимой для них среды и сетей. Кстати, если это так, то становится понятным, почему сам замысел и первая разработка роботов создается писателями фантастами. Они осуществляют первую, пока еще художественную и потому свободную от рациональных ограничений, сборку перечисленных здесь видов деятельности. За ними уже идут ученые, инженеры, экономисты, менеджеры.

Как я показываю в своих статьях и книгах по философии техники, современная технология складывается в «зоне ближайшего технологического развития», то есть тогда, когда складываются необходимые условия для формулирования замысла нового технического изделия и главное появляются виды деятельности, позволяющие этот замысел реализовать [6, с. 123]. Например, атомную бомбу и промышленность в СССР и США не удалось бы создать, если бы к этому времени не сложились: два крупных национальных государства, которые были в состоянии выделять на оборону и войну огромные средства, фундаментальные и прикладные технические исследования, эффективные инженерия и проектирование и ряд других моментов, в том числе даже такой как вторая мировая война, подстегнувшая исследования и разработки в области ядерных процессов. Реализация атомного советского проекта предполагала не только исследования в области ядерной физики и химии, проведение сложных расчетов, изобретение реакторов и атомной бомбы, но и создание коллективов разработчиков, закрытых городов и атомной промышленности (например, Челябинск-40, Арзамас-16), поиск и подготовку специалистов (наряду с нашими учеными и инженерами в реализации атомного проекта участвовало около 300 крупных немецких специалистов, вывезенных из побежденной Германии), принятие решения о выделении огромных средств, организацию шпионской деятельности (некоторые историки утверждают, что наши разведчики обеспечили не меньше половины успеха), создание беспрецедентной секретности, эффективное управление всем процессом и многое другое [7]. Конечным продуктом ядерного проекта являлась не только атомная бомба, т.е. инженерное сооружение, но и создание атомной промышленности и технологии в широком понимании, позволяющих создавать как атомные бомбы разного назначения, так и ядерные реакторы, в том числе и для мирных целей.

Если исходить из данной гипотезы о роли зоны ближайшего технологического развития, то становится понятным, почему в последние десятилетия началось ускоренное развитие робототехники. Вероятно, для нее сложилась зона ближайшего технологического развития. Действительно, развитие программирования, современной вычислительной техники, технологии миниатюризации, создание новых материалов, разворачивание сетей и научно-технических сред, технологическая конкуренция, концентрация капиталов и ряд других моментов позволили заново сформулировать задачи построения роботов и реально перейти к сборке в новых технологиях перечисленных видов деятельности. В результате довольно быстро стала складываться робототехника как новый современный вид технологии. В этом качестве, 


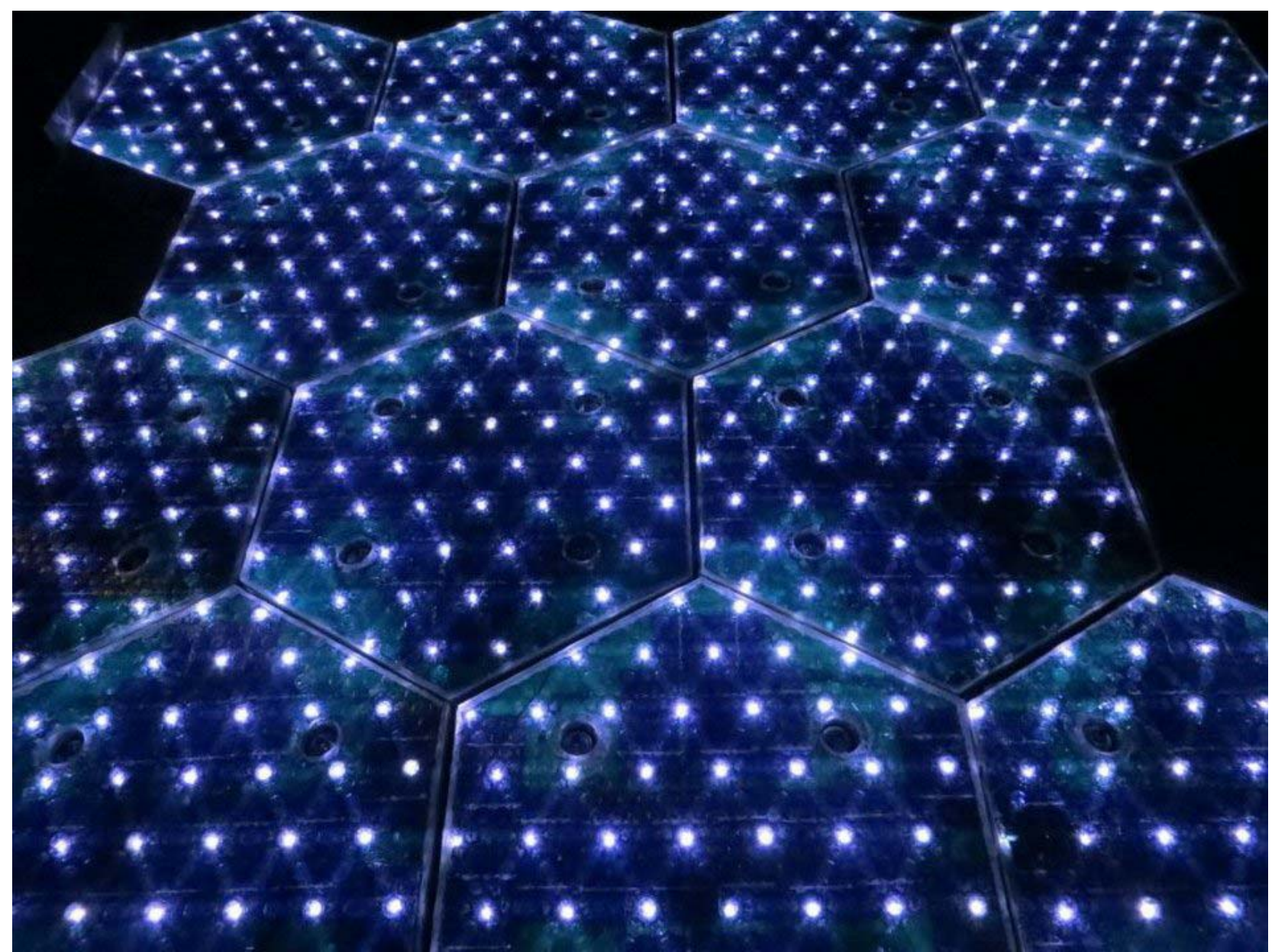

Рисунок 3

действительности, впервые. А предшествующие (опытные и инженерные) формы создания роботов можно спокойно отнести к предпосылкам робототехники.

Как обычно это бывает с новыми технологиями, и робототехника позволяет решить многие ранее не решаемые проблемы, стоящие перед современным обществом и человеком. Хорошо известны обычные области использования роботов, меньше их роль как современной технологии. Ее можно проиллюстрировать на двух не совсем обычных примерах. Один мы уже рассмотрели: использование ботов в Интернете. Другой пример, разработка большого американского проекта, который позволит, с одной стороны, получить на основе покрытия дорог солнечными батареями большие объемы чистой энергии, с другой - полностью автоматизировать поездки по стране, сделав их безопасными.

«Концепция «Солнечной дороги», предложенной Жюли и Скоттом Брюсоу (Scott, Julie Brusaw) еще в 2006 году, на первый взгляд достаточно проста и состоит в замене асфальтового полотна фотогальваническими элементами, покрываемыми сверху особым сверхпрочным текстурированным стеклом собственной разработки. За счет большой площади покрытия такие дороги смогут выполнять множество полезных функций, включая подсвечивание дорожного полотна, заправку электромобилей, поставку электроэнергии потребителю и других. Основная сложность на протяжении нескольких лет заключалась в нахождении формулы прозрачного стекла повышенной прочности. По расчетам 


\section{Тренды и управление 1(13) • 2016}

авторов проекта на пике производственных мощностей система будет способна производить втрое больше электроэнергии, чем тот объем, который сегодня потребляет США. Часть остаточных мощностей можно будет задействовать для обеспечения электропитания электрических транспортных средств, посредством передатчиков, размещаемых вдоль трассы» <...>

Согласно проекту, на этапе внедрения дорожное покрытие позволит:

Подогревать панели для удаления снега в зимнее время года.

Обеспечивать светодиодной подсветкой дорожного полотно в темное время суток.

Поддерживать работоспособность системы отвода дождевой воды с ее последующей фильтрацией.

Обеспечивать функционирование системы самоочистки от антифризов, масел и прочих загрязнителей.

Обеспечивать работу системы доставки воды для производственных и сельскохозяйственных нужд.

Организовать подзарядку электромобилей от солнечных панелей в любом месте трассы.

Оповещать о неисправности солнечных модулей при помощи сигнальной системы.

Подсвечивать животных, внезапно появившихся на дороге» [8].

Понятно, что подобные дороги могут быть созданы только с использованием робототехники. По сути, они являются, в том числе, и не совсем обычными роботами.

«Компания Google Inc. в последние годы вполне удачно развивала проект «Google Driverless Car». В рамках этой программы были созданы пробные поистине уникальные комплексы для транспортных средств, которые позволяют перемещаться автомобилям по городским и загородным трассам без какого-то участия со стороны человека.

Уже сейчас компания создала, как минимум двенадцать удачных автомобилей, которые являются полностью роботизированными: для их управления не нужен человек. Более того, эти «беспилотники» проехали уже более 300 тысяч миль. При этом нет никаких данных о том, что были какие-то происшествия на дороге с участием этих авто.
Управляют движением транспортных средств, как и всеми имеющимися системами, специальные компьютеры. Все данные по поводу необходимой навигации они получают непосредственно со спутников, принадлежащих службам гео-позиционирования. Умеют эти компьютеры также обмениваться информацией между собой.

Эксперты уверены, что уже к 2025 году на улицах крупных городов могут появиться автономные автомобили. К тому же, кроме частных авто и грузовиков, «беспилотниками» может стать даже транспорт, который относится к специализированному: снегоуборочные машины, дорожная техника, автомобили различных экстренных служб. Не исключено, что все они смогут «научиться» действовать по ситуации самостоятельно» [9].

Вряд ли кто-нибудь будет спорить с тезисом, что подобные проекты в силах реализовать только богатые и развитые в техническом отношении страны. В результате золотой миллиард может еще больше оторваться в своем развитии от остальных стран. Но уже сегодня опережение в технологическом развитии позволяет даже такой маленькой стране как Израиль создавать гражданские и военные роботы, которые управляют рядом заводов (например, химическими, как правило, они полностью автоматизированы и роботизированы), перехватывают ракеты террористов, ведут разведку, уничтожают солдат противников.

Однако, роботы обоюдоострое оружие. Многие системы самолетов, которые таранили 11 сентября башни в США, как известно, роботизированы. Хакеры создают боты-вирусы тоже не только в развитых странах. А что касается военных конфликтов между странами, обладающими развитыми технологиями, то каждой воюющей стороне кажется, победа в значительной степени зависит от ее технологического опережения. Поэтому, не случайно, что японский изобретатель робота-собаки Aibo Масахиро Фудзита (2003) из лаборатории Sony выступает с заявлением о недопустимости использования роботов в ситуациях конфликта, подобных войне в Ираке или Сирии. Пока еще трудно понять, размышляет он, могут ли роботы биться друг с другом, но посредством Интернета хакер или какой-другой 


\section{Теория и методология управления}

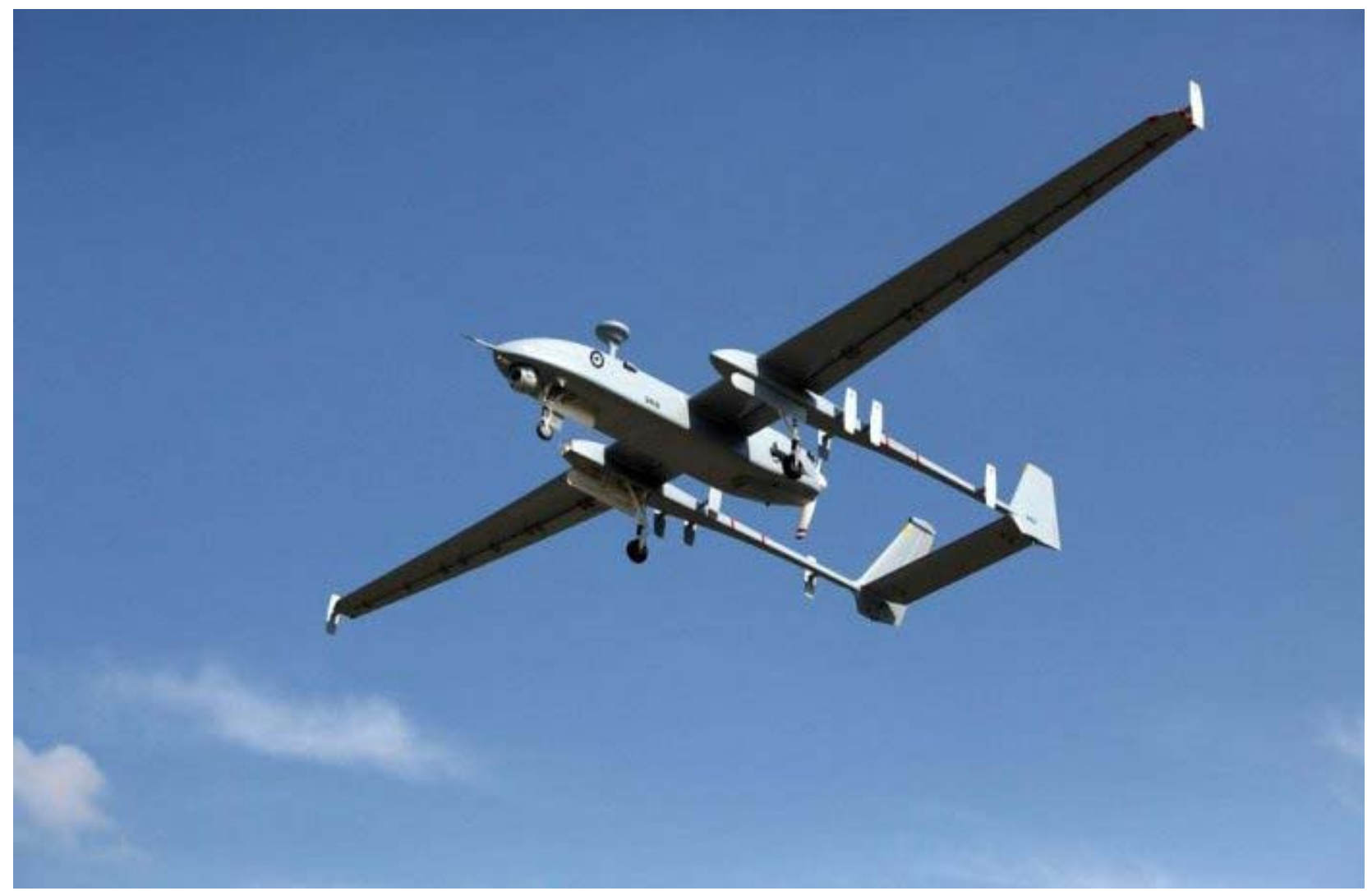

Рисунок 4

плохой парень может легко управлять ими и вредить людям.

Роботизация, безусловно, способствует продвижению в решение такой важной глобальной задачи как снижение негативных последствий от технического развития. Но вряд ли развитие робототехники снимет эту проблему совсем. Все-таки, как я утверждаю, робототехника - это современная технология, развитие которой, как и всякой другой технологии, ну, возможно, в меньшей мере, влечет за собой негативные последствия. Например, при изготовлении тех же солнечных батарей в отходах производства накапливается кадмий, мышьяк и некоторые другие токсические вещества, кроме того, под батареи приходится отчуждать территорию.

Заканчивая это эссе о робототехнике, еще раз хочу обратить внимание на то, что за проек- тированием и созданием роботов стоят сети и системы - электрические, коммуникационные, инфраструктурные, экономические, социальные, что обычно не видно, виден только продукт - роботы. А сети и системы, хотя, отчасти, тоже создаются, в значительно большей степени представляют собой естественные образования, жизнь и особенности которых мы пока плохо понимаем. Вместо ясных и понятных законов робототехники в настоящее время можно формулировать только некоторые установки, адресованные их разработчикам. Например, такие: степень автономии роботов должна быть такая, которая в любой момент позволяет эту автономию ограничить и прервать; роботы не самостоятельные субъекты, а проектируемые и контролируемые технические среды (изделия среды); робототехника - наше социальное тело. 


\section{Тренды и управление 1(13) • 2016}

\section{Библиография}

1. http://refleader.ru/qaspolqaspol.html

2. EC. N 26 (705). 2016. C.11.

3. Розин В.М. Как в настоящее время можно осмыслить концепцию искусственного интеллекта? // Искусственный интеллект: междисциплинарный подход. М., 2006. С. 194-208.

4. http://www.osp.ru/news/2012/0928/13015012/

5. Розин В.М. Три этапа формирования технологии в культуре нового времени // Тренды и управление. N4. 2015. С. 336-347.

6. Розин В.М. Эволюция инженерной и проектной мысли. Инженерия: Становление, Развитие, Типология. М., 2015. 200 с.

7. http://ru.wikipedia.org/wiki/ Создание советской атомной бомбы

8. http://www.pvsm.ru/dopolnennaya-real-nost/102104/print

9. http://news.bcm.ru/auto/2012/11/19/632093/1

10. Урванов Г.А., Даньшин В.В., Дюмин А.А., Чепин Е.В. Система взаимодействия с человеком, как агентом мобильного робототехнического комплекса // Программные системы и вычислительные методы. - 2015. - 1. - C. 45 - 51. DOI: 10.7256/2305-6061.2015.1.13986.

\section{References (transliterated)}

1. http://refleader.ru/qaspolqaspol.html

2. ES. N 26 (705). 2016. S.11.

3. Rozin V.M. Kak v nastoyashchee vremya mozhno osmyslit' kontseptsiyu iskusstvennogo intellekta? // Iskusstvennyi intellekt: mezhdistsiplinarnyi podkhod. M., 2006. S. 194-208.

4. http://www.osp.ru/news/2012/0928/13015012/

5. Rozin V.M. Tri etapa formirovaniya tekhnologii v kul'ture novogo vremeni // Trendy i upravlenie. N4. 2015. S. 336-347.

6. Rozin V.M. Evolyutsiya inzhenernoi i proektnoi mysli. Inzheneriya: Stanovlenie, Razvitie, Tipologiya. M., 2015. $200 \mathrm{~s}$.

7. http://ru.wikipedia.org/wiki/ Sozdanie sovetskoi atomnoi bomby

8. http://www.pvsm.ru/dopolnennaya-real-nost/102104/print

9. http://news.bcm.ru/auto/2012/11/19/632093/1

10. Urvanov G.A., Dan'shin V.V., Dyumin A.A., Chepin E.V. Sistema vzaimodeistviya s chelovekom, kak agentom mobil'nogo robototekhnicheskogo kompleksa // Programmnye sistemy i vychislitel'nye metody. - 2015. - 1. - C. 45 - 51. DOI: 10.7256/2305-6061.2015.1.13986. 